Research Article

\title{
Analyzing the Effects of Cross-Border E-Commerce Industry Transfer Using Big Data
}

\author{
Cuimin Wang (D) \\ School of Economics and Management, Hebei Chemical \& Pharmaceutical College, Shijiazhuang 050026, China \\ Correspondence should be addressed to Cuimin Wang; wcm001@stu.ahu.edu.cn
}

Received 22 March 2021; Revised 23 April 2021; Accepted 30 May 2021; Published 17 June 2021

Academic Editor: Fazlullah Khan

Copyright (c) 2021 Cuimin Wang. This is an open access article distributed under the Creative Commons Attribution License, which permits unrestricted use, distribution, and reproduction in any medium, provided the original work is properly cited.

\begin{abstract}
With the increasing diversification and personalization of consumer demand in the international market, coupled with the rapid development of the internet, the many advantages of cross-border e-commerce as an emerging trading model have become more apparent. When the hybrid system synergy model is based on the effective combination of the systems, the overall performance is greater than the sum of various elements' simple superposition. As the upstream chain of modern logistics, cross-border e-commerce requires its virtual characteristics to develop in the direction of informationization, automation, and intelligence. Only when they are interdependent and mutually promoted can they achieve greater synergy. The regional difference measurement theory is often used to measure the effect of cross-border e-commerce industry transfer. First, build a cross-border e-commerce industry transfer effect measurement model to analyze the development level of China's cross-border e-commerce, for example, the measurement model of commercial industry transfer effects from 2001 to 2016. It is mainly because the development of modern logistics lags behind cross-border e-commerce, resulting in the inability of cross-border e-commerce and modern logistics to form an orderly coupling in the system structure and function. Therefore, to better promote the coordinated development of cross-border e-commerce and modern logistics, it is necessary to stimulate the functions of various subsystems and promote the synergy and deep integration of multiparty entities such as government, enterprises, and industry associations.
\end{abstract}

\section{Introduction}

Since the outbreak of the financial crisis in 2008, the global economy has been weakening, China's economic downward pressure has continued to increase, and the import and export trade market has continued to slump. After the first negative growth in foreign trade in 2009, negative growth reappeared in 2015. In sharp contrast, China's cross-border e-commerce has been developing at a fast rate, and its total transaction volume has increased by $32 \%$ annually, far higher than the annual growth rate of $7.7 \%$ in foreign trade. According to data released by the General Administration of Customs in March 2016, cross-border e-commerce import transactions increased 16 times year-on-year in 2015, and export transactions increased by 4.9 times year-on-year. As a new trading method, cross-border e-commerce, relying on the advantages of the Internet, can break through time and space restrictions and provide a more open multilateral market, which has become an important engine to promote China's foreign trade industry. With the development of cross-border e-commerce, consumers are increasingly demanding cross-border consumer product certification and logistics service timeliness, experience, and cost $[1,2]$. However, China's logistics infrastructure construction is relatively weak, and supporting services are still not perfect. In particular, cross-border e-commerce transaction lines need to go through many links such as warehousing, distribution, customs clearance, and commodity inspection, resulting in high operating costs. In addition, due to the multilevel demand for logistics services by cross-border e-commerce, such as multi-enterprise-to-consumer model (B2C) cross-border e-commerce, its small-volume, highfrequency logistics demand characteristics increase the logistics enterprise operating costs. SCHU, Matthias, and others discussed the research on international networked e-commerce from resource-based influencing factors. In this 
way, the e-commerce industry's finances can be brought into a global perspective [3].

The existing literature has extensively explored the advantages of $\mathrm{O} 2 \mathrm{O}$ or channel integration. At the same time, it also found that in the process of multichannel management, there are problems caused by unreasonable resource allocation and conflicting information in the channel, which ultimately affects the enterprise. From the perspective of consumers, some scholars explore the factors that influence consumers' choice of channels. However, research on how businesses choose between traditional sales models, e-commerce, and $\mathrm{O} 2 \mathrm{O}$ models is rarely seen [4]. In addition, this issue is a strategic decision-making issue that concerns whether companies can continue to have a competitive advantage. Therefore, this paper attempts to explain and answer this question from the perspective of game theory. Under what conditions should we adopt a simple form of e-commerce? Under what conditions should we adopt traditional sales channels? Under what conditions should we adopt a combination of online and offline sales? [5]. International industrial transfer under the product division of labor provides a new way for China to participate in the international division of labor. Theophilou and others discussed the technical problems of e-commerce based on synchrotron and focal plane array and solved the related technical problems in e-commerce operations [6]. China can not only undertake labor-intensive industries or products; it can also give full play to its comparative advantages and undertake capital- and technology-intensive industries or production links. The international industrial transfer under the product division of labor has brought opportunities for the adjustment of industrial structure $[7,8]$. Through measures, such as introduction, digestion, absorption, and independent innovation, China can promote industrial structure expansion in China's capital- and technology-intensive industries from low value-added links such as processing and assembly to independent value-added links such as independent R\&D and manufacturing.

In recent years, along with the development of China's regional economy, industrial problems have emerged, and industrial transfer research has rapidly warmed up in the country, gradually developing into a research hotspot. In general, domestic scholars' current research status in this field is to reevaluate the theory, while the foreign research is more theoretical and less empirical; the foreign countries started earlier, but the results are scattered in various subject areas and a theoretical system has not been formed. Marchet et al. propose an omnichannel commercial logistics model to analyze e-commerce logistics, which solves the cumbersome problems of e-commerce logistics and increases the orderliness of logistics $[9,10]$. How to integrate domestic research with international practice and realize the perfect combination of theory and evidence in the exploration of industrial transfer is a significant issue before us [11]. This paper reviews the progress of industrial transfer research at home and abroad, tries to summarize the three major areas of industrial transfer research, and evaluates the recent research status to benefit industrial transfer theory development. We define a single sales channel as a single mode of traditional store sales or e-commerce sales [12]. Hybrid sales have been defined as a model in which merchants mix traditional sales and e-commerce sales channels. Since the $\mathrm{O} 2 \mathrm{O}$ model is a form of high integration of online and offline channels, this paper proposes a cross-border e-commerce industry transfer effect measurement based on sales channels' perspective [13]. Most enterprises engaged in crossborder e-commerce logistics in China are mainly based on a certain business or a special line. The service resources have been severely divided. It is difficult to form an integrated logistics service system, which cannot effectively aggregate business flow, information flow, capital flow, and physical logistics [14]. Therefore, it is of great significance to clarify the measurement of the transfer effect of the cross-border e-commerce industry from the perspective of sales channels and evaluate the level of synergy.

With the increasing diversification and personalization of consumer demand in the international market, coupled with the rapid development of the internet, the many advantages of cross-border e-commerce as an emerging trading model have become more apparent [15]. The regional difference measurement theory is used to measure the effect of cross-border e-commerce industry transfer and effectively improve the operation of the e-commerce industry by establishing a measurement model [16].

The research contributions of this paper include the following:

(1) Propose a logistics analysis method based on a hybrid system collaboration model. Based on the system's effective combination, the overall performance will be greater than the sum of individual elements' simple superposition. As the upstream chain of modern logistics, cross-border e-commerce needs its virtual characteristics to develop informatization, automation, and intelligence. Only by interdependence and mutual promotion can we achieve greater synergy.

(2) The paper puts forward the regional difference measurement theory and applies it to the measurement of the effect of cross-border e-commerce industry transfer.

(3) Constructed a measurement model for the effect of cross-border e-commerce industry transfer and researched the development level of cross-border e-commerce in my country.

The rest of this paper is organized as follows. Section 2 discusses the related work. Section 3 introduces the construction of the measurement model of the crossborder e-commerce industry transfer effect. Section 4 shows the experimental simulation results, and Section 5 concludes the paper with a summary and future research directions. 


\section{Related Work}

This section gives a brief review of the various transfer effects of the cross-border e-commerce industry. At present, the representative research on the relationship between crossborder e-commerce and modern logistics mainly focuses on the following aspects [17]. First is the role of logistics in cross-border e-commerce. For example, Parker and Colin emphasized the important role of logistics intermediaries in the e-commerce logistics channel; Alding and Stall discussed marketing channels and logistics platforms in e-commerce [18]. The second is supply chain coordination. For example, Prazak believes that e-commerce and logistics companies' coordinated development is conducive to resource integration and supply chain optimization. Amni analyzes how to improve supply chain management through mobile applications.

The third is the opportunity for the development of the Belt and Road. For example, Niu et al. [19] believed that the Belt and Road Initiative is conducive to interconnection and reducing foreign trade cost based on the trade facilitation perspective. Huang et al. [20] pointed out that the development of cross-border e-commerce in China under the "Belt and Road" initiative is relatively balanced. Madden et al. [21] used Guangdong as an example to explore the relationship and development of international trade and logistics under this strategy's influence.

The fourth is the emerging cross-border logistics model and assessment. Kasemsap [22] established a logistics service capability evaluation system based on the cross-border e-commerce logistics service model analysis. Wang and Luo [23] believed that cross-border e-commerce and logistics should be promoted by the operation of overseas warehouses and other logistics models. The fifth is the evolution of competition between e-commerce and logistics. For example, Yang and Lee [24] carried out evolution research on e-commerce logistics channels, and Yang et al. [25], based on microenterprise perspective dynamic evolution game analysis, shows that the interest mechanism between e-commerce enterprises and logistics enterprises should have been optimized [26].

The above research provides the research basis and reference for this paper and leaves a large room for expansion. On the one hand, most of the research focuses on the one-way impact of modern logistics on cross-border e-commerce and cross-border e-commerce logistics problems with new logistics models. On the other hand, research methods are primarily qualitative analysis, while quantitative analysis uses simple linear correlation analysis and other methods to demonstrate the relationship between the two. The indicators are relatively simple; it is difficult to measure the mutual influence relationship [27]. Based on the existing research results, this paper establishes a cross-border ecommerce and modern logistics synergy evaluation model based on a composite system synergy model, which effectively measures the level of synergy between the two. Factors provide relevant countermeasures to promote the coordinated development [28].

\section{Research Basis and Literature Review}

3.1. Definition of Related Concepts. Cross-border e-commerce refers to business activities in which different trading entities in the territory use the internet to realize commodity transactions through e-commerce platforms, conduct online payments, ensure transportation of goods, and conclude transactions through cross-border logistics. Drawing on Haken's synergy definition, this paper examines the linkage state and the process between cross-border e-commerce and modern logistics from a systematic perspective. It focuses on the degree of consistency [29]. The order parameter is the total contribution of each subsystem's coordinated movement, reflecting the ordered type and structure of the system. The size of the order parameter measures the order degree of the system. The rapid development of cross-border e-commerce requires the support of modern logistics, and it, in turn, drives the upgrading and upgrading of modern logistics. The two are interdependent and mutually promoted [30]. Under the product division of labor, China can rely on its comparative advantages to integrate some capital-intensive product value chains that cannot produce at this stage and even leapfrog the industry across certain value chain links to promote the industry [31]. Under this pattern, China can use the international industrial transfer to give play to the demonstration effects, spillover effects, and competitive effects of multinational corporations, improve domestic enterprises' technological level, develop relevant domestic-related industries, and establish and develop modern industries more quickly and effectively. Under the product division of labor, China can gradually increase the proportion of capital- and technologyintensive products in total domestic output and optimize the industrial structure by undertaking labor-intensive links in capital- and technology-intensive products [32].

Cross-border e-commerce has a very important strategic significance as a technological foundation for promoting economic integration and trade globalization. Cross-border e-commerce has broken through the obstacles between countries and made international trade move to borderless trade. At the same time, it is also causing tremendous changes in world economic trade [33]. For enterprises, the open, multidimensional, and three-dimensional multilateral economic and trade cooperation mode of cross-border e-commerce has greatly expanded the path of entering the international market. It greatly promotes the optimal allocation of multilateral resources and mutual benefit and winwin between enterprises in Figure 1. Cross-border e-commerce makes it very easy for them to access other countries' information and buy affordable goods [34].

3.2. Regional Difference Measure Model. For a long time, influenced by the international economic situation and the practice of international industrial transfer, the definition of early industrial transfer mostly stayed where developed countries have advantages. Later, the practice of industrial transfer was no longer confined to a single declining industry but gradually expanded to an expansionary industry and 


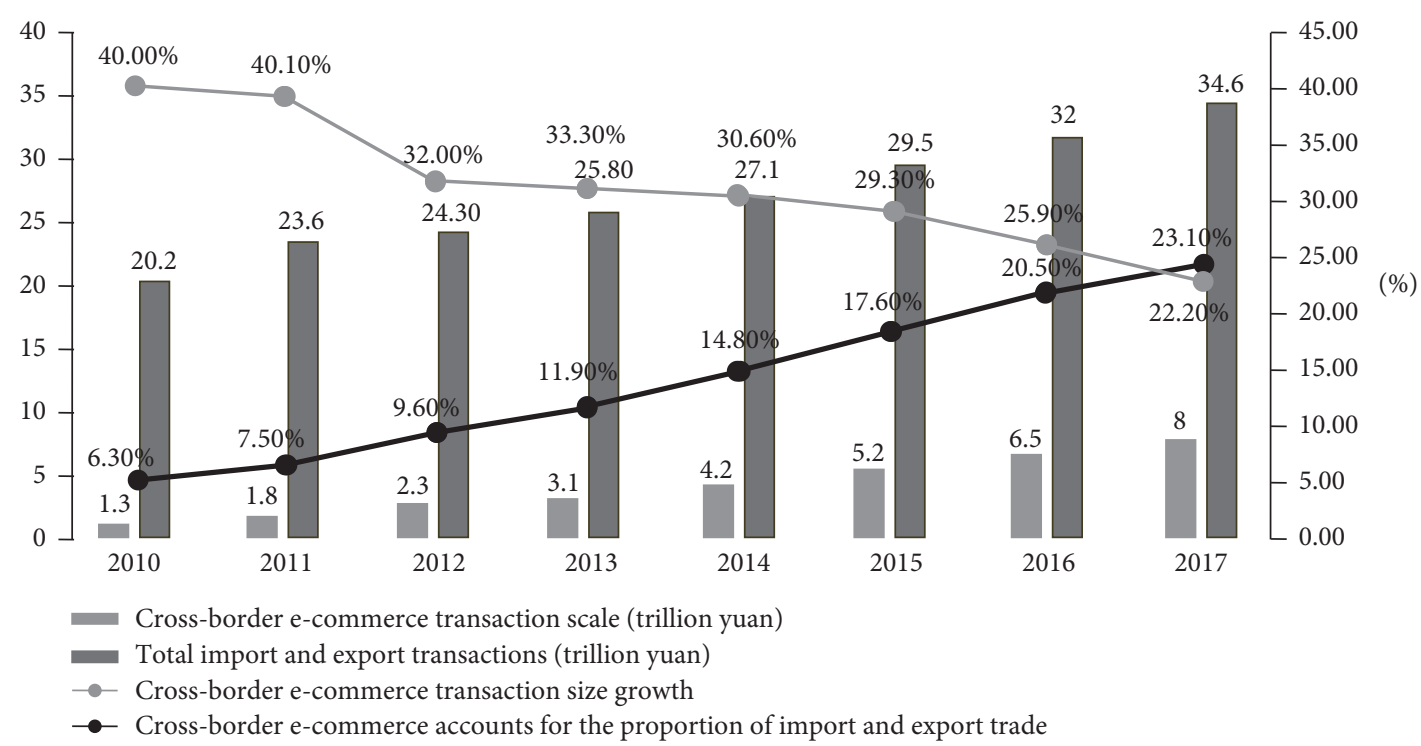

FIGURE 1: Import and export trade scale of cross-border e-commerce.

gave a more comprehensive description of the industry in terms of nature, methods, and effects. With regional economic theory development, there are more and more statistical methods for assessing regional differences [35]. The most common regional difference measurement models are coefficient of variation (or the weighted coefficient of variation), Gini coefficient, and Tyre index [36]. The coefficient of variation is the dispersion of the mean of all distances. It reflects to a large extent the degree of difference in the speed of development and the distribution characteristics. It can be used to decompose the indicators for measuring regional differences. The Gini coefficient is different from the coefficient of variation. It does not take the deviation of the mean but the difference for all pairs of comparisons. It then adds all the absolute gaps and divides by the number of all regions (the total number of regions) and the average of regional indicators [37]. The Thali index is also a method used by domestic and foreign scholars to measure regional economic development differences. Therefore, this study uses the weighted coefficient of variation $\left(\mathrm{CV}_{\mathrm{w}}\right)$, Gini coefficient $(G)$, and the Tyra index $(T)$ three parameters. Their calculation formulas are as follows:

$$
\begin{aligned}
\mathrm{CV}_{w} & =\frac{1}{\mu} * \sqrt{\frac{\sum_{i=1}^{n}\left(y_{i}-\mu\right)^{2} * P_{i}}{\sum_{i=1}^{n} P_{i}}}, \\
G & =\frac{1}{2 n^{2} \mu} \sum_{i=1}^{n} \sum_{j=1}^{n} n_{i} n_{j}\left|y_{i}-y_{j}\right|, \\
T & =\sum_{i=1}^{n} \frac{P_{i}}{P} \log \left(\frac{\mu}{y_{i}}\right),
\end{aligned}
$$

where $\mu$ means the per capita GDP, $P_{i}$ is the proportion of the population of each city $i$ and county to the total population $P$ of the province, $n$ is the number of all counties and cities, $n_{i}$ and $n_{j}$ are the proportion of the county's population $i$ and $j$, respectively, to the total population of the province, and $y_{i}$ and $y_{j}$ are the per capita GDP of the county and the city, respectively.

\section{Construction of the Measurement Model for the Transfer Effect of the Cross-Border E-Commerce Industry}

4.1. The Image-Driven Transfer Function Method. In imagedriven transmission, network transmission security is very important. The sources of network and communication security risks are mainly identified from the three aspects of network and security equipment hardware, software, and network communication protocols. These three aspects play a decisive role in the transmission of network information. As the infrastructure of network communication, network, and security equipment, its hardware performance, reliability, and network structure design determine the efficiency of data transmission to a certain extent. The risks brought about by network communication protocols are more reflected in the design flaws of the protocol layer. Although this defect's failure probability is very low, once the problem occurs, it is very serious.

To measure the development level of China's crossborder e-commerce industry transfer effect effectively, we first need to construct a corresponding order parameter index system. The selected indicators need to characterize each subsystem's development level to measure cross-border e-commerce and modern logistics correctly. This paper draws on the research results according to each subsystem's characteristics and the availability of relevant index data. It compares the representative cross-border e-commerce evaluation index system of industry transfer effect to initially select cross-border e-commerce development. Modern logistics service capabilities, as the order parameters of the cross-border e-commerce subsystem and modern logistics subsystem, measure the development capabilities of the cross-border e-commerce system with 12 indicators such as 
total volume, quality, potential, and structure. Scale, infrastructure, informatization level, three dimensions, 12 indicators, and evaluation of cross-border e-commerce system service are given in Table 1. In addition, Figure 2 shows the business process for cross-border e-commerce transactions.

4.2. Methodological Study. The traditional Malmquist TFP index has been around for a long time, and the Swedish economics and statistician Malmquist used the index to analyze consumption changes over time [27]. Based on this,
Caves, Christensen, and Diewert proposed the Malmquist Total Factor Productivity (Malmquist TFP) index, but it has not been taken seriously. The nonparametric linear programming algorithm proposed by Färe, Grosskopf, Norris, and others reinjects the index. This method has been widely used in various industries, departments, and international comparisons in finance, public administration, and agriculture.

In general, the expression of the Malmquist TFP index is as follows:

$$
\begin{aligned}
M\left(x^{t+1}, y^{t+1}, x^{t}, y^{t}\right) & =\left[\left(\frac{D^{t+1}\left(x^{t}, y^{t}\right)}{D^{t+1}\left(x^{t+1}, y^{t+1}\right)}\right)\left(\frac{D^{t}\left(x^{t}, y^{t}\right)}{D^{t}\left(x^{t+1}, y^{t+1}\right)}\right)\right]^{1 / 2} \\
& =\frac{D^{t}\left(x^{t}, y^{t}\right)}{D^{t+1}\left(x^{t+1}, y^{t+1}\right)}\left(\frac{D^{t+1}\left(x^{t+1}, y^{t+1}\right)}{D^{t}\left(x^{t+1}, y^{t+1}\right)} \frac{D^{t+1}\left(x^{t}, y^{t}\right)}{D^{t}\left(x^{t}, y^{t}\right)}\right)^{1 / 2},
\end{aligned}
$$

where $D$ represents the distance function, which is a tool for studying multi-input and multi-output technology systems without any assumptions about producer behavior. Shephard (1970) defined a distance function based on production functions, which are later widely used. Zhou pointed out that the Malmquist TFP index is based on the distance function and can be directly measured by input-oriented or outputoriented traditional DEA models, which is the basis of the current Malmquist TFP index calculation. . However, as mentioned above, the traditional DEA model has certain flaws, which makes it difficult for the Malmquist TFP index to exert its true value. Therefore, this paper introduces the idea of industrial transfer effect measurement into the measurement of the Malmquist TFP index and establishes a new total factor productivity measurement model that considers efficiency evaluation, regional ordering, and time-series analysis. The traditional industry transfer effect measurement is based on solving the traditional DEA model, and its shortcoming is that it cannot be ranked effectively. It is more practical when avoiding the cross-efficiency DEA model secondary target selection. Suppose a decision unit is represented by $(1 \leq j \leq n)$, each decision unit will have an input and an output. Considering each decision-making unit as a "participant" in the game, the participant's efficiency value can be calculated by the traditional CCR model. Assuming that the efficiency value of the participant and the efficiency value of the rest of the participants remain maximum at the same time, the participation effect is the best.

Suppose there is a decision unit $n, \mathrm{DMU}_{j}$ represented by $(1 \leq j \leq n)$; each decision unit has an input $m$ and an outputs. The input and output vectors of the decision unit $j$ are represented by ${ }_{x}^{i j}(i=1, \ldots, m)$ and ${ }_{y}^{r j}(r=1, \ldots, s)$, respectively. Considering each decision-making unit as a "participant" $\mathrm{DMU}_{d}$ in the game, the participant's efficiency value $\alpha_{d}$ can be calculated by the traditional CCR model.
Assume that the efficiency value of the participants and the effieciency value of the remaining participants are maximized as $\mathrm{DMU}_{j}$, while maintaining the same efficiency value $\mathrm{DMU}_{j}$. The cross-competitive efficiency value $\mathrm{DMU}_{j}$ obtained by the weights is as follows:

$$
\alpha_{d j}=\frac{\sum_{r=1}^{s} \mu_{r j}^{d} y_{r j}}{\sum_{i=1}^{m} \omega_{i j}^{d} x_{i j}}, \quad d, j=1, \ldots, n,
$$

in which $\mu_{r j}^{d}$ and $\omega_{i j}^{d}$ are the feasible weights of the model. For the calculation of $\alpha_{d j}$, we need to consider the following mathematical planning questions:

$$
\begin{aligned}
& \operatorname{Max} \sum_{r=1}^{s} \mu_{r j}^{d} y_{r j} \\
& \text { s.t. } \sum_{i=1}^{m} \omega_{i j}^{d} x_{i j}-\sum_{r=1}^{s} \mu_{r j}^{d} y_{r j} \geq 0, \quad j=1, \ldots, n, \\
& \sum_{i=1}^{m} \omega_{i j}^{d} x_{i d}=1, \\
& \alpha_{d} \times \sum_{i=1}^{m} \omega_{i j}^{d} x_{i d}-\sum_{r=1}^{s} \mu_{r j}^{d} y_{r j} \leq 0, \\
& \omega_{i j}^{d} \geq 0, \quad i=1,2, \ldots, m, \\
& \mu_{r j}^{d} \geq 0, \quad r=1,2, \ldots, s,
\end{aligned}
$$

where $\alpha_{d} \leq 1$ represents the calculation parameters of the iterative algorithm. Initially, its initial value $\mathrm{DMU}_{d}$ is determined as the traditional cross-efficiency value, and after it converges, the value becomes the cross-competitive efficiency value.

The following is a Malmquist exponential formula based on the Industrial transfer effect measurement, denoted as CC-Malmquist. 
TABLe 1: Cross-border e-commerce evaluation index system.

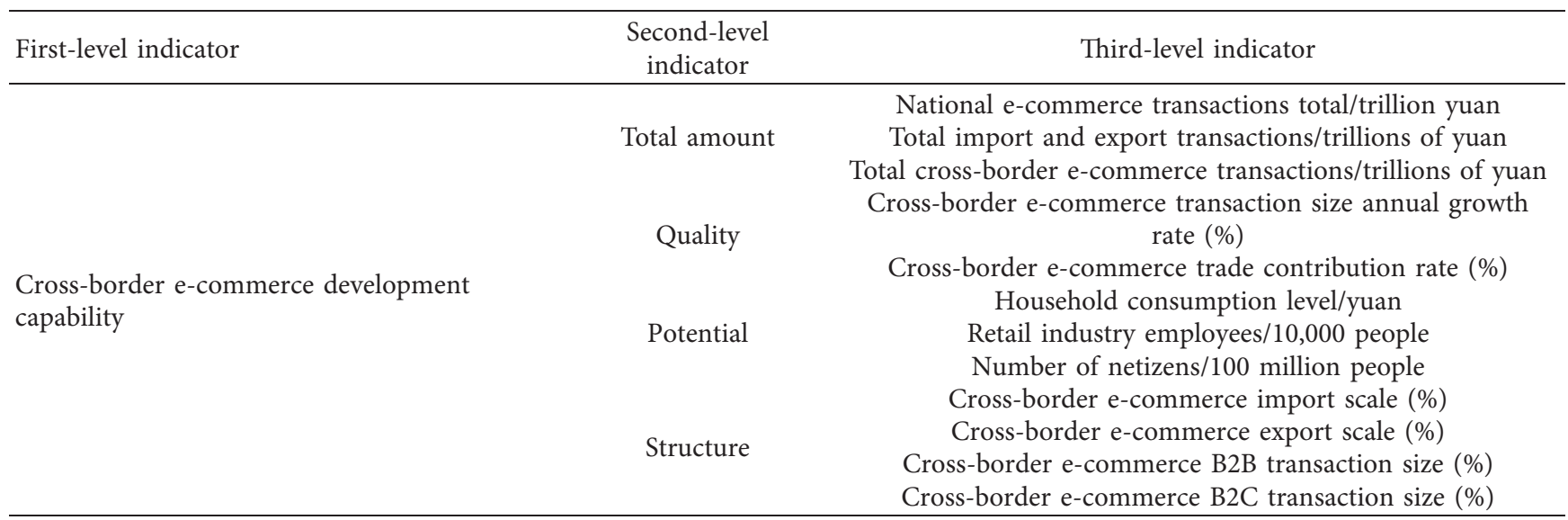

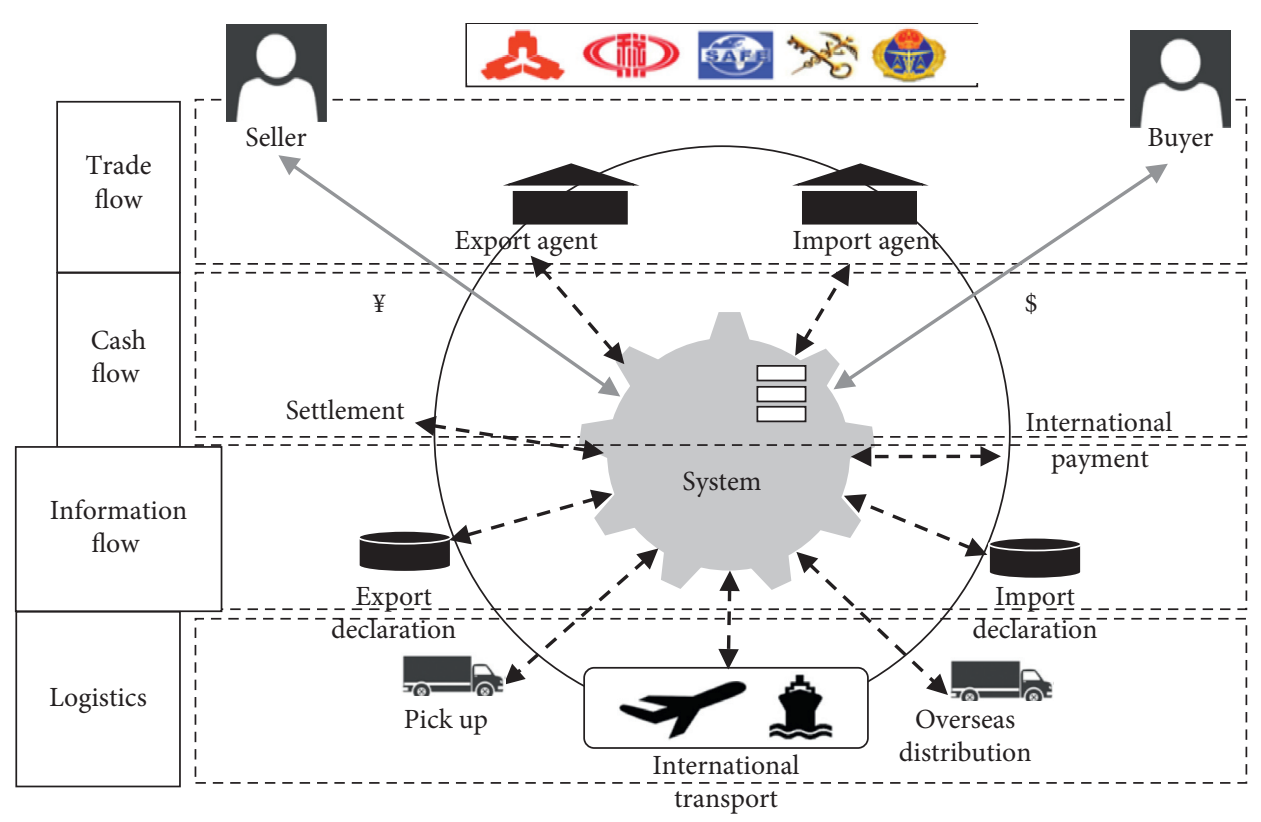

Figure 2: Business process for cross-border e-commerce transactions.

$$
\begin{aligned}
C C-M_{k}\left(x^{t+1}, y^{t+1}, x^{t}, y^{t}\right) & =\left[\left(\left(\frac{E_{k}^{t+1}\left(x^{t}, y^{t}\right)}{E_{k}^{t+1}\left(x^{t+1}, y^{t+1}\right)}\right)\left(\frac{\left.E_{k}^{t}\left(x^{t}, y^{t}\right)\right)}{E_{k}^{t}\left(x^{t+1}, y^{t+1}\right)}\right)\right]^{1 / 2}\right. \\
& =\frac{E_{k}^{t}\left(x^{t}, y^{t}\right)}{E_{k}^{t+1}\left(x^{t+1}, y^{t+1}\right)}\left(\frac{E_{k}^{t+1}\left(x^{t+1}, y^{t+1}\right)}{E_{k}^{t}\left(x^{t+1}, y^{t+1}\right)} \frac{E_{k}^{t+1}\left(x^{t}, y^{t}\right)}{E_{k}^{t}\left(x^{t}, y^{t}\right)}\right)^{1 / 2} .
\end{aligned}
$$

4.3. Empirical Analysis. In the past 40 years of reform and opening up, China's cross-border e-commerce supply and demand have shown rapid growth due to China's rapid economic growth. Looking back at history, during the 34 years from 1978 to 2011, China's GDP grew at an average annual rate of $9.8 \%$ at comparable prices, creating a miraculous growth that has attracted worldwide attention. However, China has paid a huge price for high economic growth in many aspects, such as resources and the environment. According to statistics, at least $80 \%$ of China's
GDP growth in the past has been obtained by relying on "overdraft" of resources and the ecological environment. Factors such as emphasizing the economy, neglecting the environment, and excessive pursuit of output value development have made the environmental resources overloaded. The interprovincial cross-border e-commerce consumption situation in China is as follows. The continuous growth of China's extensive economy has brought unprecedented pressure on resources and the environment. Therefore, cross-border e-commerce efficiency has become one of the 
issues of general concern to the Chinese government and the international community. China's vast territory and different geological structures have formed the basic characteristics of China's cross-border e-commerce resources: one is widely distributed, and the other is an uneven distribution. The composition of cross-border e-commerce consumption in various regions has inextricably linked with the distribution of cross-border e-commerce structure types.

The cross-border e-commerce intensity, that is, the "cross-border e-commerce-GDP" indicator, refers to the cross-border e-commerce required for unit economic output. It belongs to the cross-border e-commerce efficiency index under the single factor productivity framework. Because it is simple in calculation and strong in operability, it is the most commonly used mixed indicator for measuring the efficiency of cross-border e-commerce in a country or region. Here, we present the interprovincial cross-border e-commerce intensity values for representative years in China, as shown in Table 2.

China's cross-border e-commerce products mainly include 3C electronic products, maternal and child health products, cosmetics, shoes and hats, home gardening, outdoor products, and auto parts. 3C electronic products have the characteristics of high standardization and low return rate and are suitable for sale through e-commerce channels. Manufacturers of corresponding cross-border e-commerce are also the main producers and manufacturers of these commodity categories. At present, in the field of cross-border e-commerce, bank payment, credit card payment, third-party payment, and other payment methods coexist. Among them, cross-border e-commerce B2B currently completes transactions in the traditional offline mode. The payment methods are mainly credit card and bank transfer such as Western Union. Cross-border e-commerce B2C primarily uses online payment methods to complete transactions, and third-party payment tools have been widely used. The main characteristics of supply chain finance have realized e-commerce, combining logistics and capital flow, and financial zing logistics. Each platform, such as supply chain data, financial networks, transaction standardization, multiple standardized manifests, standardized mortgages, and platform specialization, has its own characteristics, some are large vertical e-commerce platforms, and some are vertical consumption platforms. The characteristics of supply chain finance are based on subversion, and the transaction process of enterprises is transferred to supply chain finance. The whole process of capital and logistics is controlled, and closed-loop control is realized. The customer's order service on the Alibaba platform combined with short-term export credit insurance financing and factoring as an entry point: the order is the starting point of a transaction once the overseas buyer orders through the Alibaba platform. With the order as the chain, the foreign trade inquiry is matched, and the order management is carried out. The logistics supply chain and fund settlement form a closed loop, enabling process traceability and quality control, which ultimately protects the transactions between buyers and sellers. The financial framework of the crossborder e-commerce supply chain is shown in Figure 3.
TABle 2: The Chinese interprovincial cross-border e-commerce.

\begin{tabular}{lcccccc}
\hline & 2001 & 2004 & 2007 & 2010 & 2013 & 2016 \\
\hline Beijing & 1.67 & 1.04 & 0.80 & 0.57 & 0.54 & 0.49 \\
Tianjin & 1.70 & 1.41 & 1.11 & 0.80 & 0.78 & 0.74 \\
Hebei & 2.20 & 1.93 & 1.96 & 1.52 & 1.47 & 1.35 \\
Shanxi & 4.09 & 4.02 & 2.95 & 2.14 & 2.12 & 1.83 \\
Inner Mongolia & 2.53 & 2.35 & 2.48 & 1.66 & 1.58 & 1.44 \\
Liaoning & 2.28 & 1.94 & 1.87 & 1.30 & 1.26 & 1.13 \\
Jilin & 2.07 & 1.85 & 1.65 & 1.12 & 1.06 & 0.96 \\
Heilongjiang & 1.90 & 1.65 & 1.46 & 1.20 & 1.22 & 1.08 \\
Shanghai & 1.21 & 1.07 & 0.91 & 0.73 & 0.69 & 0.65 \\
Jiangsu & 1.00 & 0.91 & 0.92 & 0.72 & 0.69 & 0.62 \\
Zhejiang & 1.09 & 0.92 & 0.90 & 0.70 & 0.68 & 0.61 \\
Anhui & 1.61 & 1.51 & 1.21 & 0.94 & 0.88 & 0.79 \\
Fujian & 0.88 & 0.78 & 0.94 & 0.76 & 0.73 & 0.67 \\
Jiangxi & 1.25 & 1.06 & 1.06 & 0.77 & 0.76 & 0.67 \\
Shandong & 1.33 & 1.08 & 1.28 & 0.99 & 0.96 & 0.89 \\
Henan & 1.54 & 1.43 & 1.38 & 1.05 & 1.01 & 0.93 \\
Hubei & 1.47 & 1.59 & 1.51 & 1.13 & 1.06 & 0.95 \\
Hunan & 1.10 & 1.22 & 1.40 & 1.07 & 1.02 & 0.93 \\
Guangdong & 0.98 & 0.84 & 0.79 & 0.64 & 0.62 & 0.58 \\
Guangxi & 1.30 & 1.18 & 1.22 & 0.93 & 0.91 & 0.83 \\
Hainan & 0.93 & 0.74 & 0.92 & 0.76 & 0.75 & 0.66 \\
Chongqing & 1.53 & 1.61 & 1.42 & 1.12 & 1.08 & 0.99 \\
Sichuan & 1.63 & 1.59 & 1.53 & 1.20 & 1.15 & 1.04 \\
Guizhou & 4.31 & 3.59 & 3.25 & 1.99 & 1.93 & 1.78 \\
Yunnan & 1.77 & 1.70 & 1.73 & 1.32 & 1.30 & 1.20 \\
Shan'xi & 1.64 & 1.65 & 1.44 & 1.01 & 0.98 & 0.88 \\
Gansu & 3.06 & 2.45 & 2.26 & 1.69 & 1.62 & 1.44 \\
Qinghai & 3.40 & 2.99 & 3.07 & 2.24 & 2.17 & 1.90 \\
Ningxia & 4.44 & 3.45 & 4.14 & 2.68 & 2.50 & 2.18 \\
Xinjiang & 2.44 & 2.25 & 2.11 & 1.69 & 1.76 & 1.52 \\
\hline & & & & & &
\end{tabular}

In terms of index selection, the number of sample sizes must be no less than twice the evaluation indicators. Fully considering data availability and drawing on the cross-border e-commerce, labor, and capital, three-factor production function ideas are established. Based on the comprehensive theory, the following input-output indicator system has been constructed: one of the output indicators is the region's actual GDP. There are three input indicators, namely, capital investment, cross-border e-commerce investment, and labor input. The actual GDP of the region uses each region's annual GDP data to reflect the output level of each decision-making unit. Considering the issue of comparability, this paper takes 2007 as the base period. It uses the regional GDP index and flattens it to obtain the constant local price's real GDP in 2007. Capital investment is measured by capital stock. The currently widely used method is to calculate each province's capital stock and city at constant prices using the perpetual inventory method after estimating a base year. Hsiao et al. systematically estimated the interprovincial physical capital stock in China [16]. This method has gradually developed into a reference system for many scholars to estimate the capital stock. Its calculation formula is as follows:

$$
K_{i t}=K_{i t-1}\left(1-\delta_{i t}\right)+I_{i t}
$$

where $i$ is the cross-sectional dimension, representing 30 regions. $t$ is used for the time-series dimension, from 2001 to 2016; $K$ means the capital stock; $\delta$ represents the 


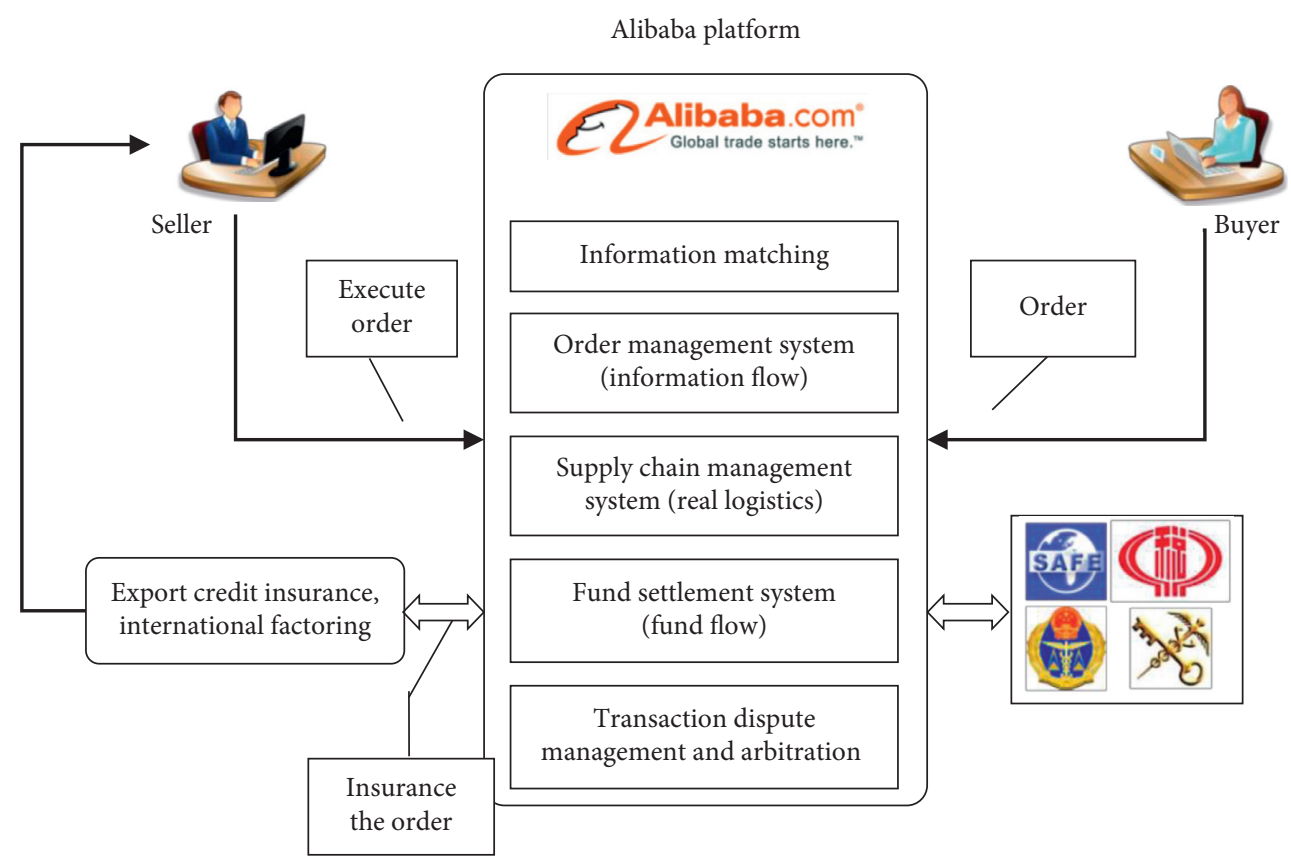

FIgURE 3: Cross-border e-commerce supply chain financial framework.

depreciation rate, which here is $9.6 \% ; I$ is an investment, the fixed capital is used to form the total replacement. This paper calculates the physical capital stock of each region from 2001 to 2016. It uses the fixed asset price index to reduce the investment in each year and convert it into the actual value of the constant price based on 2001. The cross-border e-commerce investment is expressed by the total amount of cross-border e-commerce consumption in each region. The original data units are uniformly converted into 10,000 tons of standard coal. Labor investment, in the literature on cross-border e-commerce efficiency measurement, is mostly measured by the number of regional employees; few scholars consider labor quality. For example, Chu [38] pointed out in selecting indicators: because the per capita education level of the provinces and other data are not available, the differences in labor quality between provinces are ignored. However, the number of employees in the region can only measure the amount of labor input in the region and cannot reflect any information about the labor quality. Therefore, this paper integrates labor quality into the measurement system of labor input and constructs a comprehensive indicator that reflects the quantity and quality of labor to reflect the social reality more objectively and truly, thus obtaining a more scientific and persuasive research result. In summary, the input-output indicator system is shown in Table 3.

4.4. Test and Result. The formation of industrial belts is a distinctive feature of regional economic development, while infrastructure, central cities, and tertiary industries are the main components. To this end, according to the connotation of the industrial belt, the main driving forces for the formation and evolution of the Jiangsu industrial belt can be compared and analyzed from the aspects of resource development, infrastructure, central city, technological progress, and export-oriented economy. As the command center, service center, and regulation center of regional economic development, the central city is an important industrial belt node. With the growth of the central city's economy and the expansion of its scale, the diffusion effect is increasing, and the organization drives the economic development of the radiation region. Increasingly, central cities with higher development levels often bring out industrial belts with higher levels of development. The cities along the Yangtze River and Shanghai-Nanjing industrial belt are densely populated and economically developed. Among them, there are 2 mega-cities, 4 large cities, 8 medium-sized cities, 7 small cities along the Yangtze River, and several established towns. Urban population and builtup area: it has reached 12.1253 million and 1467.41 square kilometers, respectively; there are 4 megacities, 2 medium cities, 1 small city, and several established towns in the Shanghai-Nanjing industrial belt. The urban population and built-up area have reached 11.954 million and 1415.16 square kilometers. The coastal and eastern Bohai Sea industrial belts are populated and economically developed in the north of Jiangsu Province. There are 1 megacity, 1 large city, and 2 medium cities along the East Longhai Sea. The built-up area reached 2,904,700 and 400.08 square kilometers, respectively; the construction of the coastal industrial belt started late, and the overall development level of the city is lagging. There are only 3 large cities, 4 medium cities, 10 small cities, and an urban population. The area of the district is 4,375,700 and 1,590.94 square kilometers, respectively. Therefore, large- and medium-sized cities in the four major industrial belts' urban axis system are developed and have various functional types. There are both national-level industrial bases and comprehensive regional cities, which constitute the Jiangsu industrial belt's basic skeleton. 
TABLE 3: Input-output indicator system.

\begin{tabular}{lc}
\hline Input indicator & Output indicator \\
\hline Capital: interprovincial material capital stock & GDP: actual regional GDP \\
Labor: labor input with labor quality & \\
Cross-border e-commerce: total interprovincial cross-border e-commerce consumption &
\end{tabular}

To comprehensively compare the impact of the above five kinds of dynamics on the formation and development of industrial belts in Jiangsu Province, a linear regression model and an entropy method were used to comprehensively and quantitatively analyze them. From five aspects: resource development promotion, infrastructure guidance, central city traction, science and technology promotion, and outward development. Taking 2001-2016 as the research period, the main dynamic process of the formation and development of the industrial belt since implementing the regional common development strategy in Jiangsu Province has been evaluated. According to the weights of each evaluation index and its normalized value, the comprehensive value is shown in Figure 4, and the dynamic value of the formation and development dynamics of the crossborder e-commerce industry transfer belt in Jiangsu from 2001 to 2016 have been calculated, respectively. Figure 5 shows the main dynamics of the formation and development of major industrial belts in Jiangsu. Analyze the evolution process of Jiangsu's cross-border e-commerce industry transfer formation and development momentum.

It can be seen from Figures 4 and 5 that, as time goes by, cross-border e-commerce trade accounts for an increasing proportion in the whole trade. With the continuous development of e-commerce, more and more transactions are transferred from offline to online, and e-commerce trade takes an increasingly dominant position.

4.5. Discussion and Suggestion. Under the new normal, promoting the coordinated development of cross-border e-commerce and modern logistics is a complex system engineering, which requires the cooperation and deep integration of multiparty entities such as government, enterprises, and industry associations. At present, it is urgent to construct a modern logistics integrated service system to realize the orderly coupling of the cross-border e-commerce and modern logistics in the system structure and function to maximize the synergy between cross-border e-commerce and modern logistics. It is important to construct a coordinated development path and strive to achieve an interactive development of cross-border e-commerce and modern logistics.

4.5.1. Improve Government Resource Support. First, strengthen the construction of cross-border e-commerce infrastructure. Give priority to supporting information infrastructure projects such as network broadband so that they can enjoy the policy dividends brought about by the Belt and Road Initiative strategy. It will guide Internet information technology innovation, enhance R\&D and independent innovation capabilities, and apply innovation results to

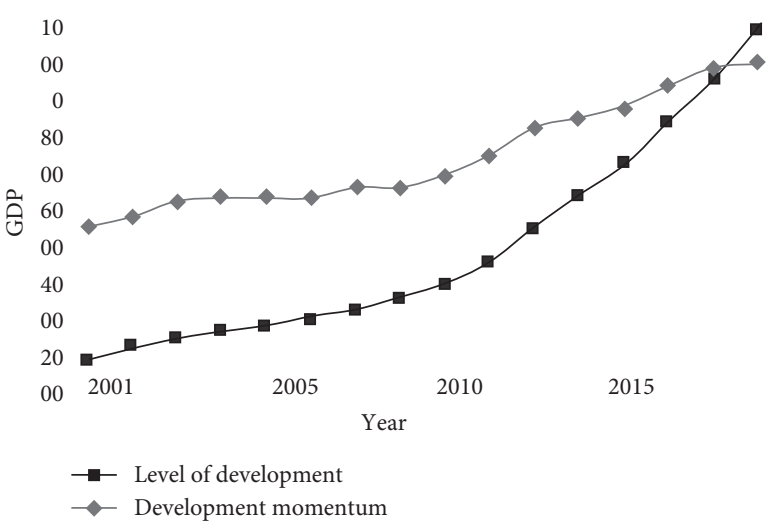

Figure 4: Economic development level and development momentum of major industrial belts in Jiangsu Province.

practice. Better serve cross-border e-commerce. Second, improve the comprehensive service system for cross-border logistics. Establish a one-stop large customs clearance port for multi-sector cooperation to improve the commodity circulation rate. Encourage domestic express logistics companies to cooperate with internationally renowned companies to provide more high-quality and efficient cross-border logistics services. Third, develop cross-border e-commerce industrial parks. The organic management $\mathrm{f}$ information flow, logistics, and capital flow can effectively play its role. It is strengthening information and promoting regular declarations to create more profit space for cross-border e-commerce enterprises. And, promote dynamic management. The government should also actively participate in constructing online trade zones, establish coordination mechanisms with other participating countries and regions, and promote consumer rights protection with sound policies and regulations; establish an integrated trade growth model to help SMEs integrate into international trade.

4.5.2. Optimize the Enterprise Service Platform. First, build an integrated platform to promote industrial integration. The shortcomings of cross-border e-commerce logistics in China are mainly complicated processes, long distances, and low circulation efficiency. The platform has been connected to the wiring and information flow under the logistics system. The information platform of logistics, business flow, and logistics ensure the smooth operation of the crossborder e-commerce logistics supply chain. Secondly, innovate cross-border logistics services and rationally choose logistics services. Cross-border logistics enterprises should integrate resources and establish a one-stop integrated service system to meet various cross-border consumers' multilevel needs. 


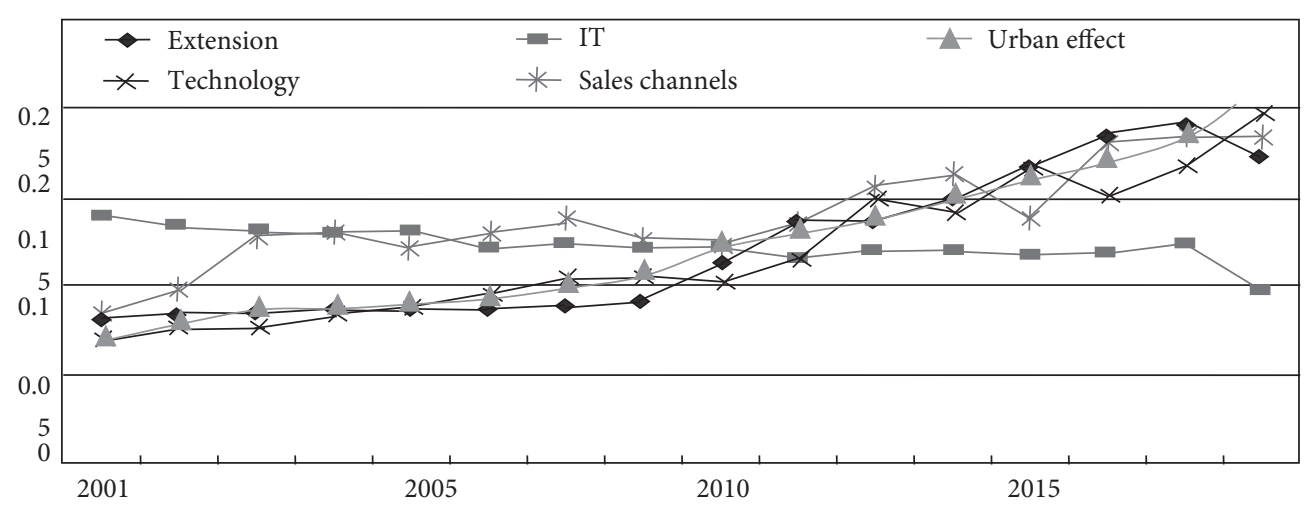

Figure 5: Comparison results of different models.

In addition to line logistics, it is also possible to promote overseas models and establish overseas warehousing bases in countries and regions where trade with China is frequent. In this way, the goods only need to be transferred to warehouses at two fixed locations when entering and leaving the country. The types of demand for environmental e-commerce users determine the logistics mode. For example, ordinary postal services are used for the low-end consumer goods in the B2C mode and the international air express service is used for high-end luxury goods. It is also possible to use two or more modes in combination and adjust them in due course.

4.5.3. Enhance Multiparty Collaboration. The coordinated development of cross-border e-commerce and modern logistics requires the joint efforts of governments, enterprises, and industry associations to enhance integration. At present, the synergy between multiparty entities needs to focus on the following two aspects: first, strengthen talent cultivation. Governments, universities, enterprises, industry associations, and other stakeholders work closely to improve the diversified talent cultivation mechanism. They highlight government-policy-oriented functions, university personnel training functions, corporate and industry association practices and training functions, and cultivating diversified channels. The second is to strengthen market orientation. The ultimate goal of cross-border e-commerce and modern logistics collaboration is to achieve more efficient development and create more social and economic value. This requires us to be market-oriented and give full play to the basic functions of the resource allocation market. All of them are based on market demand, strengthening information sharing and resource integration, increasing product service complementarity, and optimizing supply chains' integration. In addition, it is necessary to tap the potential needs of consumers, such as broadening consumers' overseas shopping channels and shortening overseas shopping logistics time.

\section{Conclusion}

The industrial transfer is a complex economic phenomenon involving multiple entities, multiple spaces, and multidisciplinary attributes. Therefore, the difficulty of the research is relatively high, although the research has achieved more results. As a spatial organization form of regional economic development, industrial belts' construction and development have received more and more attention and become an important factor for balanced growth and driving the regional economy. Development and other aspects have played a significant role. The construction of industrial belts has gradually become a critical organizational form for the intensive and specialized development of traditional industries and modern manufacturing industries in China and a vital force for promoting the leap-forward development of regional economies. Since the implementation of the regional common development strategy in 1994, the important position of cross-border e-commerce industry belt construction in regional economic development has risen to a considerable extent. In chronological order, the economy develops gradually. The regional economy has gradually formed a pattern of interactive development. The layout and development of cross-border e-commerce industry belts have effectively curbed the widening differences between the north and the south. While promoting the industry belt's economic status in the province, the intensity of economic interaction between industry and county has enhanced. The factors affecting the formation and evolution of cross-border e-commerce industry belts are complex and diversified. The driving force for the formation and development of industrial belts is constantly changing-gradually from single propulsion to diversification, that is, from resource development to infrastructure-based transformation.

\section{Data Availability}

The data used to support the findings of this study are included within the article.

\section{Conflicts of Interest}

The author declares that there are no conflicts of interest.

\section{References}

[1] M. Falk and E. Hagsten, "E-commerce trends and impacts across Europe," International Journal of Production Economics, vol. 170, pp. 357-369, 2015. 
[2] S. Mathews, C. bianchi, K. J. Perks, M. Healy, and R. Wickramasekera, "Internet marketing capabilities and international market growth," International Business Review, vol. 25 , no. 4 , pp. $820-830,2016$.

[3] M. Schu, D. Morschett, and B. Swoboda, "Internationalization speed of online retailers: a resource-based perspective on the influence factors," Management International Review, vol. 56, no. 5, pp. 733-757, 2016.

[4] Y. Wang, Y. Wang, and S. Lee, "The effect of cross-border E-commerce on China's international trade: an empirical study based on transaction cost analysis," Sustainability, vol. 9, no. 11, p. 2028, 2017.

[5] G. F. Watson, S. Weaven, H. Perkins, D. Sardana, and R. W. Palmatier, "International market entry strategies: relational, digital, and hybrid approaches," Journal of International Marketing, vol. 26, no. 1, pp. 30-60, 2018.

[6] G. Theophilou, C. L. Morais, D. E. Halliwell et al., "Synchrotron-and focal plane array-based Fourier-transform infrared spectroscopy differentiates the basalis and functionalis epithelial endometrial regions and identifies putative stem cell regions of human endometrial glands," Analytical and Bioanalytical Chemistry, vol. 410, pp. 1-14, 2018.

[7] D. Huo, R. Ouyang, K. Hung, and B. Sun, "Effect of crossborder E-business policy on the export trade of an emerging market: a dynamic study of institutional support to crossborder E-business at Chinese pilot cities," Emerging Markets Finance and Trade, vol. 54, pp. 1-15, 2018.

[8] L. C. Leonidou, C. S. Katsikeas, S. Samiee, and B. Aykol, "International marketing research: a state-of-the-art review and the way forward," in Advances in Global Marketing, pp. 3-33, Springer, Cham, Switzerland, 2018.

[9] M. Ruiz, "Chinese customs regulations on cross-border E-commerce: a growth opportunity for foreign enterprises and Chinese commercial platforms," Sinología Hispánica, vol. 1, no. 6, pp. 133-156, 2018.

[10] G. Marchet, M. Melacini, S. Perotti, M. Rasini, and E. Tappia, "Business logistics models in omni-channel: a classification framework and empirical analysis," International Journal of Physical Distribution \& Logistics Management, vol. 48, no. 4, pp. 439-464, 2018.

[11] G. Agag, "E-commerce ethics and its impact on buyer repurchase intentions and loyalty: an empirical study of small and medium Egyptian businesses," Journal of Business Ethics, vol. 154, pp. 1-22, 2017.

[12] W. Ai, J. Yang, and L. Wang, "Revelation of cross-border logistics performance for the manufacturing industry development," International Journal of Mobile Communications, vol. 14, no. 6, pp. 593-609, 2016.

[13] N. Yang, "Study of the impact of the cross-border E-commerce model based on the belt and Road on China's international trade system," Revista de la Facultad de Ingeniería, vol. 32, no. 8, 2017.

[14] A. Hübner, J. Wollenburg, and A. Holzapfel, "Retail logistics in the transition from multi-channel to omni-channel," International Journal of Physical Distribution \& Logistics Management, vol. 46, no. 6-7, pp. 562-583, 2016.

[15] H. Cho and J. Lee, "Searching for logistics and regulatory determinants affecting overseas direct purchase: an empirical cross-national study," The Asian Journal of Shipping and Logistics, vol. 33, no. 1, pp. 11-18, 2017.

[16] Y.-H. Hsiao, M.-C. Chen, and W.-C. Liao, "Logistics service design for cross-border E-commerce using Kansei engineering with text-mining-based online content analysis," Telematics and Informatics, vol. 34, no. 4, pp. 284-302, 2017.
[17] G. Yan, S. Lei, Y. Gao, Y. Ye, and Y. Cai, "Development path research on Shanghai's cruise supporting industry," in Report on China's Cruise Industry, pp. 177-193, Springer, Singapore, 2018.

[18] P.-J. Wu and K.-C. Lin, "Unstructured big data analytics for retrieving e-commerce logistics knowledge," Telematics and Informatics, vol. 35, no. 1, pp. 237-244, 2018.

[19] B. Niu, Y. Liu, F. Liu, and C. K. M. Lee, "Transfer pricing and channel structure of a multinational firm under overseas retail disruption risk," International Journal of Production Research, vol. 57, pp. 1-25, 2018.

[20] L. Huang, W. Zhao, G. Xie, H. Xie, and Q. Yi, "Evaluating and optimizing city E-commerce competitiveness based on FACA Model: a case from 32 cities in China," Revista de la Facultad de Ingeniería, vol. 32, pp. 298-308, 2017.

[21] G. Madden, A. Banerjee, P. N. Rappoport, and H. Suenaga, "E-commerce transactions, the installed base of credit cards, and the potential mobile E-commerce adoption," Applied Economics, vol. 49, no. 1, pp. 21-32, 2017.

[22] K. Kasemsap, "The importance of electronic commerce in modern business," in Encyclopedia of Information Science and Technology, pp. 2791-2801, IGI Global, Hershey, PA, USA, 4th edition, 2018.

[23] K. Wang and W. Luo, "The impact of open innovation on cross-organization cooperation on logistics enterprise service innovation capability-based on the perspective of manufacturing enterprise participation," China Circulation Economy, vol. 11, no. 4, pp. 50-56, 2015.

[24] H. Yang and H. Lee, "Exploring user acceptance of streaming media devices: an extended perspective of flow theory," Information Systems and e-Business Management, vol. 16, pp. 1-27, 2017.

[25] H. Yang, J. Yu, H. Zo, and M. Choi, "User acceptance of wearable devices: an extended perspective of perceived value," Telematics and Informatics, vol. 33, no. 2, pp. 256-269, 2016.

[26] H. Yang, H. Lee, and H. Zo, "User acceptance of smart home services: an extension of the theory of planned behavior," Industrial Management \& Data Systems, vol. 117, no. 1, pp. 68-89, 2017.

[27] J. Yu, H. Lee, I. Ha, and H. Zo, "User acceptance of media tablets: an empirical examination of perceived value," Telematics and Informatics, vol. 34, no. 4, pp. 206-223, 2017.

[28] H. Liang, J. Zou, K. Zuo, and M. J. Khan, “An improved genetic algorithm optimization fuzzy controller applied to the wellhead back pressure control system," Mechanical Systems and Signal Processing, vol. 142, Article ID 106708, 2020.

[29] H. Zheng, W. Guo, and N. Xiong, "A kernel-based compressive sensing approach for mobile data gathering in wireless sensor network systems," IEEE Transactions on Systems, Man, and Cybernetics: Systems, vol. 48, no. 12, pp. 2315-2327, 2017.

[30] H. Liang, J. Zou, Z. Li, M. J. Khan, and Y. Lu, "Dynamic evaluation of drilling leakage risk based on fuzzy theory and PSO-SVR algorithm," Future Generation Computer Systems, vol. 95, pp. 454-466, 2019.

[31] Y. Zhang, R. Zhu, Z. Chen, J. Gao, and D. Xia, "Evaluating and selecting features via information theoretic lower bounds of feature inner correlations for high-dimensional data," European Journal of Operational Research, vol. 290, no. 1, 2020.

[32] H. Liang, A. Xian, M. Mao, P. Ni, and H. Wu, "A research on remote fracturing monitoring and decision-making method supporting smart city," Sustainable Cities and Society, vol. 62, Article ID 102414, 2020. 
[33] Y. Zhou, D. Zhang, and N. Xiong, "Post-cloud computing paradigms: a survey and comparison," Tsinghua Science and Technology, vol. 22, no. 6, pp. 714-732, 2017.

[34] A. M. Al-Momani, M. A. Mahmoud, and M. S. Ahmad, "Factors that influence the acceptance of Internet of things services by customers of telecommunication companies in Jordan," Journal of Organizational and End User Computing, vol. 30, no. 4, pp. 51-63, 2018.

[35] M. R. Reddy, K. G. Srinivasa, and B. E. Reddy, "Smart vehicular system based on the Internet of things," Journal of Organizational and End User Computing, vol. 30, no. 3, pp. 45-62, 2018.

[36] P. Singh and R. Agrawal, "A customer centric best connected channel model for heterogeneous and IoT networks," Journal of Organizational and End User Computing, vol. 30, no. 4, pp. 32-50, 2018.

[37] C.-H. Chen, F. Song, F.-J. Hwang, and L. Wu, "A probability density function generator based on neural networks," Physica A: Statistical Mechanics and Its Applications, vol. 541, Article ID 123344, 2020.

[38] W. Chu, "MOOCS curriculum model: contribution and dilemma," Foreign Language Audio-Visual Teaching, vol. 3, no. 4 , pp. $39-40,2014$. 